\title{
David P. JORDAN, Napoleon and the Revolution
}

New York, Palgrave Macmillan, 2012, 327 p., ISBN 978-0230362819, 90 dollars

\section{Annie Jourdan}

\section{(2) OpenEdition}

\section{Journals}

\section{Édition électronique}

URL : https://journals.openedition.org/ahrf/12921

DOI : $10.4000 /$ ahrf.12921

ISSN : 1952-403X

Éditeur :

Armand Colin, Société des études robespierristes

Édition imprimée

Date de publication : 1 septembre 2013

Pagination : 234-236

ISBN : 9782200928261

ISSN : 0003-4436

Référence électronique

Annie Jourdan, « David P. Jordan, Napoleon and the Revolution », Annales historiques de la Révolution française [En ligne], 373 | juillet-septembre 2013, mis en ligne le 03 octobre 2013, consulté le 01 juillet 2021. URL : http://journals.openedition.org/ahrf/12921 ; DOI : https://doi.org/10.4000/ahrf.12921

Ce document a été généré automatiquement le 1 juillet 2021.

Tous droits réservés 


\section{David P. JORDAN, Napoleon and the Revolution}

New York, Palgrave Macmillan, 2012, 327 p., ISBN 978-0230362819, 90 dollars

\section{Annie Jourdan}

\section{RÉFÉRENCE}

David P. JORDAN, Napoleon and the Revolution. New York, Palgrave Macmillan, 2012, 327 p., ISBN 978-0230362819, 90 dollars

1 David Jordan, professeur émérite à l'Université d'Illinois de Chicago, est avant tout connu pour ses travaux sur le procès du roi et la carrière révolutionnaire de Robespierre, mais aussi pour sa monographie sur la vie et l'œuvre du baron Haussmann. Le livre recensé ici lui ouvre un domaine nouveau, celui du Premier Empire et de ses rapports avec la Révolution. L'auteur y présente une synthèse pour un large public plutôt qu'une recherche inédite, fondée sur des documents d'archives.

2 Sa thèse, directement inspirée de Hegel, est que Napoléon poursuit sans même le vouloir la Révolution et l'impose tant en France que dans les pays alliés et conquis. Le grand homme serait l'instrument inconscient de l'Histoire, l'homme providentiel. La construction et le contenu du livre tournent autour de cette idée de «ruses de l'histoire ». L'idée n'est pas nouvelle. Victor Cousin l'avait popularisée en son temps. Daniel Fabre et Alice Gérard en ont analysé les aléas dans deux superbes articles, que ne paraît pas du reste connaître Jordan. Alice Gérard, (Alice Gérard...233-309). « Le grand homme et la conception de l'histoire au XIX siècle ", Romantisme, no.100, 1998. Daniel Fabre, Pierre Centlivres et Françoise Zonabend (eds). La Fabrique des héros, Paris, 1998 ; p. 233-309). Et c'est dommage parce que cela l'entraîne à prendre pour argent comptant ce qui est vision exaltée d'un philosophe allemand, qui n'a pas eu que des admirateurs et dont on peut légitimement douter du bien-fondé des interprétations. 
3 L'idée directrice de l'auteur le conduit à survaloriser l'œuvre révolutionnaire de Napoléon, quitte à minorer celle du Directoire. Le chapitre sur cette période est pour une grande part tiré du livre de Jean Tulard sur les thermidoriens et fait silence sur les travaux novateurs entrepris depuis une vingtaine d'années par les historiens de l'Institut d'histoire de la Révolution française. Il s'agit pour l'auteur de dresser un portrait enjolivé du héros d'Italie, afin de motiver le coup d'État du 18 brumaire et de poser Bonaparte en sauveur de la Révolution. Ici l'interprétation de Patrice Gueniffey s'ajoute à celle de Tulard pour raffermir l'argumentation.

4 Jordan a sans doute raison de souligner le tempérament « jacobin » de son héros et une énergie autoritaire qui rappelle celle de la Convention montagnarde. Dans sa jeunesse, Bonaparte en effet se trouvait plus proche des jacobins que des girondins, comme nous le rappellent son opuscule Le Souper de Beaucaire. Mais de là à conclure que «tout ce qu'il fit en une quinzaine d'années procédait de et était lié à la Révolution », il y a un pas qu'il vaut mieux ne pas franchir. Certes, l'empereur des Français est contraint d'accepter une constitution mais il foule aux pieds les droits de l'homme et du citoyen lesquels disparaissent durablement de la scène européenne. Certes, Napoléon introduit le Code civil et ébranle le système féodal dans les pays où il exerce une influence mais, quand il crée la noblesse d'empire, il réintroduit la primogéniture et, surtout, il ne détruit pas partout la féodalité. Elle subsiste en Westphalie ou en Pologne notamment, où les dotations concédées par Napoléon ôtent $20 \%$ des revenus étatiques - ce qui encourage les gouvernants à freiner l'abolition de la dite féodalité. À Naples, Napoléon encourage même son frère Joseph à accorder des titres féodaux aux Français qui l'entourent pour les fidéliser. Quant aux libertés publiques, elles sont de plus en plus menacées par les prisons d'État et la censure. Dans ces prisons d'État, 2500 personnes sont encore détenues en 1814 sans avoir reçu leur jugement. Et n'oublions pas non plus que Bonaparte rétablit l'esclavage dès le Consulat. L'Empire qui se dit encore républicain n'est en rien révolutionnaire. L'hérédité elle-même trahit le républicanisme affiché et pousse Napoléon à changer progressivement de cour. Dès lors, c'est le Versailles de Louis XIV qui l'obsède plus que tout autre chose.

5 L'auteur accorde également un chapitre à l'interprétation de la Révolution telle que la conçoit Napoléon à Sainte-Hélène, où il a toutes les raisons de s'en donner pour l'héritier. Pourtant, l'exilé lui-même nuance ces propos, quand il se décrit comme « l'arbitre » entre les rois et les peuples, comme celui en qui s'incarnaient l'ancien et le nouveau. Et de fait, bien des mesures prises lors du règne font penser à celles des despotes éclairés. Napoléon était un homme des Lumières, ce qui ne veut pas dire qu'il demeurait fidèle à la Révolution. Celle-ci ne dominait nullement sa pensée, ainsi que le suggère l'auteur. C'est plutôt l'obsession de sa légitimité qui le possédait. De là le mariage autrichien. La thèse donc ne convainc pas. Reste que le livre est une synthèse utile des ouvrages parus depuis une vingtaine d'années, mais avec des préférences marquées pour certains auteurs au détriment des autres. Cela-même annonce la couleur. 